\title{
Comparative Assessment of Water Quality of Tube wells and Pipe Borne Water in Kaluvankeni Hostels, Eastern University, Sri Lanka
}

\author{
S Arasaretnam* and K Cavisana \\ Department of Chemistry, Faculty of Science, Eastern University, Sri Lanka \\ *Email:s_arasaretnam@yahoo.co.uk
}

\begin{abstract}
This study was carried out to assess the water quality of tube wells and pipe borne water supplied in the hostels of Kaluvankeni, Eastern University, Sri Lanka using physicochemical parameters such as temperature, pH, Electrical Conductivity, Salinity, TDS (Total Dissolved Solids), Total Hardness, Dissolved Oxygen (DO), Turbidity, and quantitative studies of some specific cations $\left(\mathrm{Ca}^{2+} \mathrm{Mg}^{2+}, \mathrm{Fe}^{2+}, \mathrm{Cr}^{3+}, \mathrm{Cd}^{2+}, \mathrm{K}^{+}\right)$and anions $\left(\mathrm{NO}_{3}{ }^{-}, \mathrm{NO}_{2}^{-}, \mathrm{PO}_{4}{ }^{3-}, \mathrm{Cl}^{-}, \mathrm{F}^{-}\right)$. The sampling was carried out for two times per week for four weeks during the period from March to July 2020. Water samples were collected from three stations in hostels and were analyzed separately using standard methods. The results showed that both tube wells exceeded the permissible threshold levels of salinity, DO, turbidity, iron, potassium, and chromium while only tube well 2 exceeded the permissible threshold levels of conductivity. Pipe borne water was within the permissible threshold levels of all the parameters. The root causes for high turbidity in Tube well water was due suspensions from soil due to the frequent drawings from them. High level of iron concentrations could possibly be as a result of corrosions of iron pipes and may be due to the ground water contaminations from burial mounds. The obtained values of each parameter were compared with the standard values set by the World Health Organization (WHO) and Sri Lankan Standard for Drinking water (SLS 614:2013). Overall, the pipe borne water was safe for the consumption while the water from both tube wells were not advisable for consumptions but they can be used for nonconsumable purposes.
\end{abstract}

Keywords — Dissolved Oxygen, Ground water, Physicochemical, Total Hardness

\section{INTRODUCTION}

Most water in Earth's atmosphere and crust comes from the World Ocean's saline seawater, while fresh water accounts for nearly $1 \%$ of the total. Because the oceans that cover roughly $71 \%$ of the area of Earth reflect blue light, Earth appears blue from space, and is often referred to as the blue planet and the Pale Blue Dot. An estimated 1.5 to 11 times the amount of water in the oceans may be found hundreds of kilometers deep within the Earth's interior, although not in liquid form (Peel et al., 2004). Therefore, only 0.3 percent is fresh water and is suitable for consumption. However, 98 percent of fresh water is present as ground water. Ground water is the fossil water which is trapped in earth's crust in deeper layer for several centuries and is replenished by heavy rain or melting of ice. The rainy and melted water enters through the crevices present in fractured rock, gravel, sand and sandstones eventually leading to the increase in the water table (Foster et al., 2003) According to the WHO/UNICEF report on "Joint Monitoring Program for Water Supply and Sanitation-2000," only 76.1 percent of the urban population was supplied through pipe line supply compared to 11.4 percent in rural areas, while the urban and rural populations using underground well-water were estimated at 22.4 percent and 71.8 percent respectively. Unlike surface water contamination, if any contamination takes place in ground water the quality of water cannot be restored back easily. Therefore, quality and quantity of ground water should be monitored frequently to ensure the drinking water is contamination free. The hostels are located in Kaluvankeni area which is a coastal region of Batticaloa district with an elevation of $+10 \mathrm{~m}$ from Mean Sea Level. The sources of pollution can be classified into point sources or non- point sources. The possible point sources of contamination experienced in these hostels can be due to septic systems, landfills, over exploitation of tube wells, sea water intrusion and groundwater water contamination from nearby burial grounds. Likewise, the possible non-point sources can be due to the improper agricultural practices such as pesticide and insecticides. The hostellers in Kaluvankeni have reported in several incidents that, the poor quality of water supplied in hostels may have led to diseases faced by the students and also it may be the reason for staining of white clothes of the students. The students have also reported that the supplied water is smelly and yellowish in colour. The tiles of bathroom floors have become dull and yellowish and sometimes the water is not filtered and with suspended particles.

The prime objective of our research is to assess the water quality of tube wells and pipe borne water in Kaluvankeni hostels by using physicochemical parameters during the period from March to July while it is specifically aimed to assess suitability of tube well water quality for consumptions by examining the water whether it has any heavy metal contaminations, and to identify the root causes if polluted and to assess its statistical significance.

\section{MATERIALS AND METHODOLOGY}

\section{A. Site description and Sample Collection}

Water samples were collected from two tube wells (Tube well 1 at Latitude: $7 \circ 81^{\prime} 14^{\prime \prime} \mathrm{N}$, Longitude: 81 59' 03'E and Tube well 2 at Latitude: 7० 81' 17'N, Longitude: 81.59' 05'E) and drinking water from tap (Latitude: 7० 81' 11'N, Longitude: $81^{\circ}$ $\left.59^{\prime} 07^{\prime \prime} \mathrm{E}\right)$. Kaluvankeni area is located in the eastern coast of 
Sri Lanka with an elevation around $+10 \mathrm{~m}$ MSL. These hostels possess two tube wells functioning currently for daily activities and tap water is used for consumption purposes. The dimension of these two tube wells is of 1 inch width and the other tube well of $1 \frac{1}{2}$ inch width. The pumped water is distributed among 540 hostellers. Both the tube wells are located within the $1 \mathrm{~km}$ radius from the burial mounds and coconut farming practices are also carried out near the hostels. Both the stations are located within $1 \mathrm{~km}$ distance from the sea. Water samples were collected in dark polyethylene bottles, brought to the laboratory, processed within 1-2 hours, and was stored at $-20^{\circ} \mathrm{C}$ for further analysis. The water samples for DO determinations were collected in dark glass bottles and oxygen was fixed with $\mathrm{Mn}\left[\left(\mathrm{H}_{2} \mathrm{O}\right)_{6}\right]^{2+}$ and $\mathrm{NaOH} / \mathrm{KI}$ and brought to the laboratory for further analysis.

\section{B. Physicochemical analysis}

Following physico-chemical parameters were studied. Temperature, pH, Electrical Conductivity (EC), Total Dissolved Solids (TDS) and Salinity of the water was measured by $\mathrm{HACH} 40 \mathrm{~d}$ multiparameter (USA) with the respective probes. Dissolved Oxygen (DO) was measured by Sodium thiosulphate titration methods. Total Hardness as $\mathrm{CaCO} 3$ was measured by titration method using Ethylene Diamine Tetra Acetic acid (EDTA). The turbidity was measured by turbidity meter (German) in NTU. The concentration of $\mathrm{Cd}^{2+}, \mathrm{Mg}^{2+}, \mathrm{Cr}^{3+}, \mathrm{Fe}^{2+}, \mathrm{K}^{+}$were measured using SensAA GBC (Germany) model spectrometer. The water samples were sent to National Water Supply and Drainage for the determination of $\mathrm{NO}_{3}{ }^{-}, \mathrm{NO}_{2}{ }^{-}, \mathrm{PO}_{4}{ }^{3-}, \mathrm{F}^{-}, \mathrm{Cl}^{-}$ concentrations. One Way ANOVA tests were performed in order to find the statistical significance at $95 \%$ confidence levels using MINITAB 17.10.

\section{RESUltS AND DISCUSSION}

The water samples were analyzed for physicochemical parameters such as Temperature, $\mathrm{pH}, \mathrm{EC}, \mathrm{TDS}$, Salinity, Total Hardness as $\mathrm{CaCO} 3$, Turbidity, $\mathrm{NO}_{3}^{-}, \mathrm{NO}_{2}{ }^{-}, \mathrm{PO}_{4}{ }^{3-}, \mathrm{F}^{-}, \mathrm{Cl}^{-}$, $\mathrm{Fe}^{2+}, \mathrm{Mg}^{2+}, \mathrm{Ca}^{2+}, \mathrm{K}^{+}, \mathrm{Cr}^{3+}$ and $\mathrm{Cd}^{2+}$. The tabulated summary of the mean measured values of each parameter of the selected tube wells and pipe borne water samples in the study area are given in Table 1.

In the present study, the pipe borne water was colourless and odourless but the samples collected from Tube wells were slightly yellowish and foul smelling. However, this was suspected to be due to the suspended particles and due to the presence of ironic compounds.

The temperature variations in the sample may have direct or indirect effects on the solubility of ions. The mean temperatures of Tube well $2(29.963 \pm 0.568){ }^{\circ} \mathrm{C}$ is higher compared to the other two; which are Tube well 1 $(29.825 \pm 0.676){ }^{\circ} \mathrm{C}$ and Pipe borne water (P) $(28.725 \pm 1.043)$ ${ }^{\circ} \mathrm{C}$. This may be to the depth of tube well 2 (28 feet) is higher than that of tube well 1 (18 feet). Therefore, the tube well closer to the center of the earth is warmed up due to magna (Paul et al., 2013). The slight elevations observed in Tube well 1 (T1) and Tube well 2 (T2) may have led to the dissolution of ions into water as well as leads to the depletion of DO in tube wells (Siriwardana et al., 2019).

$\mathrm{pH}$ is an indicator of acidity or alkalinity of a water sample. According to $\mathrm{WHO}$ and SLS, the desirable $\mathrm{pH}$ range of consumable water is 6.5-8.5. The mean $\mathrm{pH}$ of the $\mathrm{T} 1$ $(6.8794 \pm 0.2184)$ is the lowest compared to other two; which are Tube well $2(6.897 \pm 0.284)$ and $\mathrm{P}(7.316 \pm 0.294)$. This may be due to the excessive usage of T1 compared to T2. The mean $\mathrm{pHs}$ of $\mathrm{T} 1$ and $\mathrm{T} 2$ are closer to the lower limit of the permissible WHO standards than P. This could be due to the carbonic acid deposit formed via reaction of carbon dioxide with rain water (Tiwari et al., 2015). Acidity also affects the conduit fixtures, and leaches harmful trace metals into water thereby triggering visual difficulties, acid taste, fabric discoloration or blue- green blemishes in sinks and water system (Durowaye et al., 2014).

The mean EC of T2 $(406.6 \pm 50.0) \mu \mathrm{S} / \mathrm{cm}$ is the higher compared to the other two, which are T1 (343.06 \pm 9.14$)$ $\mu \mathrm{S} / \mathrm{cm}$ and $\mathrm{P}(89.56 \pm 9.93) \mu \mathrm{S} / \mathrm{cm}$. Since the groundwater aquifers are located near the coastal side, the over pumping of tube wells may have a possible intrusion of sea water and due to that it may have high ionic concentration (Masaki Hayashi et al., 2004).

As per the WHO standard the permissible limit of salinity for consumption must be below $0.04 \%$. The mean salinities of T1, $\mathrm{T} 2$ and $\mathrm{P}$, are $(0.16500 \pm 0.00535) \%,(0.19437 \pm 0.02528) \%$, and $(0.03750 \pm 0.00535) \%$ respectively. Both the tube wells exceed the WHO permissible limit and show high salinity of water may be due to the possible sea water intrusion in ground water and also overexploitation of groundwater increases the contamination of ground water by increasing the salinity (Abdelkader et al., 2016). The high salinity may act as a catalyst for the corrosion of bathroom showers and taps at hostels eventually shortening the life span of plumbing and also impacts the taste of the water (Zakowski et al., 2014).

Total Dissolved Solids (TDS) in water are some organic and inorganic materials, which include minerals and ions that are dissolved in a particular quantity in water. According to the WHO standards the permissible limit of TDS in drinking water is $600 \mathrm{ppm}$ and as per Sri Lankan Standard the permissible limit of TDS is $500 \mathrm{ppm}$. The mean TDS of T2 (196.97 \pm 25.56) ppm is comparatively higher than $\mathrm{T} 1(164.48 \pm 4.78)$ $\mathrm{ppm}$ and $\mathrm{P}(43.23 \pm 4.78) \mathrm{ppm}$. This is due to the presence of high concentrations of ions in Tube well 2 compared to other tube well water and pipe borne water but all T1, T2 and P, TDS ranges lies within the permissible limit of WHO standard and SLS. Elevated levels of TDS, gives water a bitter, salty, or brackish taste. According to the WHO standards the amount of oxygen dissolved must be above $5 \mathrm{ppm}$ for a good quality of water. 
Table 1: Physicochemical parameters for 3 sampling stations

\begin{tabular}{|c|c|c|c|c|c|c|c|}
\hline & Parameter & UNIT & $\begin{array}{c}\text { Tube well } \\
1 \\
(\text { Mean } \pm \text { SD })\end{array}$ & $\begin{array}{c}\text { Tube well } \\
2 \\
(\text { Mean } \pm \text { SD })\end{array}$ & $\begin{array}{c}\text { Pipe borne } \\
\text { Water } \\
(\text { Mean } \pm \text { SD })\end{array}$ & $\begin{array}{c}\text { WHO } \\
\text { Standard } \\
2014\end{array}$ & $\begin{array}{c}\text { Sri Lankan } \\
\text { Standard } \\
\text { SLS 614:2013 }\end{array}$ \\
\hline 1 & Temperature & ${ }^{\circ} \mathrm{C}$ & $29.825 \pm 0.68$ & $29.963 \pm 0.57$ & $28.725 \pm 1.04$ & - & - \\
\hline 2 & $\overline{\mathrm{pH}}$ & Scale & $6.879 \pm 0.22$ & $6.897 \pm 0.28$ & $7.316 \pm 0.29$ & $6.5-7.5$ & $6.5-7.5$ \\
\hline 3 & Conductivity & $\mu \mathrm{S} / \mathrm{cm}$ & $343.06 \pm 9.14$ & $406.6 \pm 50.0$ & $89.56 \pm 9.93$ & - & - \\
\hline 4 & Salinity & $\%$ & $0.165 \pm 0.01$ & $0.194 \pm 0.03$ & $0.0375 \pm 0.02$ & 0.04 & - \\
\hline 5 & TDS & $\mathrm{ppm}$ & $164.48 \pm 4.78$ & $196.97 \pm 25.6$ & $43.23 \pm 4.22$ & 600 & 500 \\
\hline 6 & $\mathrm{DO}$ & $\mathrm{ppm}$ & $1.688 \pm 1.025$ & $0.890 \pm 0.628$ & $5.818 \pm 0.755$ & 18 & - \\
\hline 7 & Total hardness & $\mathrm{ppm}$ & $122.69 \pm 17.36$ & $137.88 \pm 22.33$ & $31.24 \pm 9.27$ & 500 & 250 \\
\hline 8 & Turbidity & $\overline{\text { N.T.U }}$ & $2.000 \pm 0.802$ & $2.438 \pm 1.613$ & $0.938 \pm 0.678$ & $\overline{5}$ & 3 \\
\hline 9 & Nitrates & $\overline{\mathrm{ppm}}$ & $4.343 \pm 1.145$ & $4.494 \pm 1.130$ & $6.12 \pm 3.481$ & 50 & 50 \\
\hline 10 & Nitrites & $\overline{\mathrm{ppm}}$ & $0.1010 \pm 0.12$ & $0.05325 \pm 0.03$ & $0.0414 \pm 0.02$ & 3 & 3 \\
\hline 11 & Phosphates & $\overline{\mathrm{ppm}}$ & $0.1413 \pm 0.10$ & $0.279 \pm 0.279$ & $0.1795 \pm 0.16$ & 1 & 2 \\
\hline 12 & Chlorides & $\overline{\mathrm{ppm}}$ & $24.25 \pm 4.06$ & $26.00 \pm 5.01$ & $17.50 \pm 3.96$ & 250 & 250 \\
\hline 13 & Fluorides & $\mathrm{ppm}$ & $0.2588 \pm 0.08$ & $0.4188 \pm 0.21$ & $0.1850 \pm 0.16$ & 1.5 & 1.0 \\
\hline 14 & Iron & $\mathrm{ppm}$ & $0.854 \pm 0.637$ & $0.896 \pm 0.687$ & $0.180 \pm 0.329$ & 0.3 & 0.3 \\
\hline 15 & Magnesium & $\mathrm{ppm}$ & $3.892 \pm 0.747$ & $4.110 \pm 1.300$ & $1.451 \pm 0.477$ & 50 & 30 \\
\hline 16 & Calcium & $\mathrm{ppm}$ & $49.17 \pm 6.96$ & $55.41 \pm 8.89$ & $12.29 \pm 3.57$ & - & 100 \\
\hline 17 & Potassium & ppm & $23.689 \pm 1.448$ & $19.726 \pm 1.41$ & $4.753 \pm 1.211$ & 12 & - \\
\hline 18 & Chromium & ppm & $0.306 \pm 0.442$ & $0.293 \pm 0.411$ & $0.199 \pm 0.359$ & 0.1 & - \\
\hline 19 & Cadmium & $\overline{\mathrm{ppm}}$ & $0.0145 \pm 0.029$ & $0.01238 \pm 0.023$ & $0.0091 \pm 0.02$ & 0.03 & 0.03 \\
\hline
\end{tabular}

The mean DO of $\mathrm{P}(5.818 \pm 0.755) \mathrm{ppm}$ is comparatively higher than $\mathrm{T} 1(1.688 \pm 1.025) \mathrm{ppm}$ and T2 $(0.890 \pm 0.628)$ ppm. T1 and T2 are below the WHO standard. This may be due to lack of contact with the atmospheric oxygen which results in low DO. $\mathrm{T} 1$ and $\mathrm{T} 2$ have very low DO since the temperature of both tube wells were comparatively higher than pipe borne water which results in decreased DO in both tube wells. According to WHO the maximum permissible limit of total hardness of the drinking water is $500 \mathrm{ppm}$ and according to the SLS the permissible limit of total hardness of the drinking water is $250 \mathrm{ppm}$. The high total hardness is experienced in $\mathrm{T} 2$ in 5-8 sampling attempt. This may be due to the T2 may not have been used during this period which may have resulted in natural accumulation of salts from contact with soil and geological formations but still T1, T2 and P agree with the WHO and Sri Lankan Standards (Patil et al., 2011). The mean total hardness of T2 $(137.88 \pm 22.33)$ ppm is comparatively higher than T1 (122.69 \pm 17.36$) \mathrm{ppm}$ and $\mathrm{P}(31.24 \pm 9.27) \mathrm{ppm}$ due to limestone beds. The tube well water used for domestic purposes by students has often caused white precipitate on containers, boilers. It has also made more usage of soap which led to soap salt residues on the skin (Simon et al., 2018). (Figure 1)

The measurement of turbidity (the relative clarity of water), is a vital indicator of water quality. The mean turbidity of the T2 (2.438 \pm 1.613$) \mathrm{NTU}$ is the highest compared to other two; which are T1 $(2.000 \pm 0.802)$ NTU and P $(0.938 \pm 0.678)$ NTU. (Figure 1) According to WHO T1, T2 and T3 lies within the permissible limit but according to the SLS T2 is slightly above the permissible limit. The highest turbidity is observed in sampling attempt 1 of T2. T2 has higher range of turbidity than $\mathrm{T} 1$ and $\mathrm{P}$ and this may be due to excessive pumping and the sediments such as clay and silt, fine organic and inorganic matter, algae, and other microscopic organisms present in T2 were not allowed to set due to the frequent usage by students (Robert et al., 2007). Prolonged usage of high turbid water may 
cause clogging in pipes. Turbidity has also led to the foul smelling and dull colouration of tube well water. Turbidity can cause pathogens and phytoplankton to multiply since it is rich in nutrients. Higher turbidity in water can also cause gastrointestinal diseases such as cholera, diarrhea.

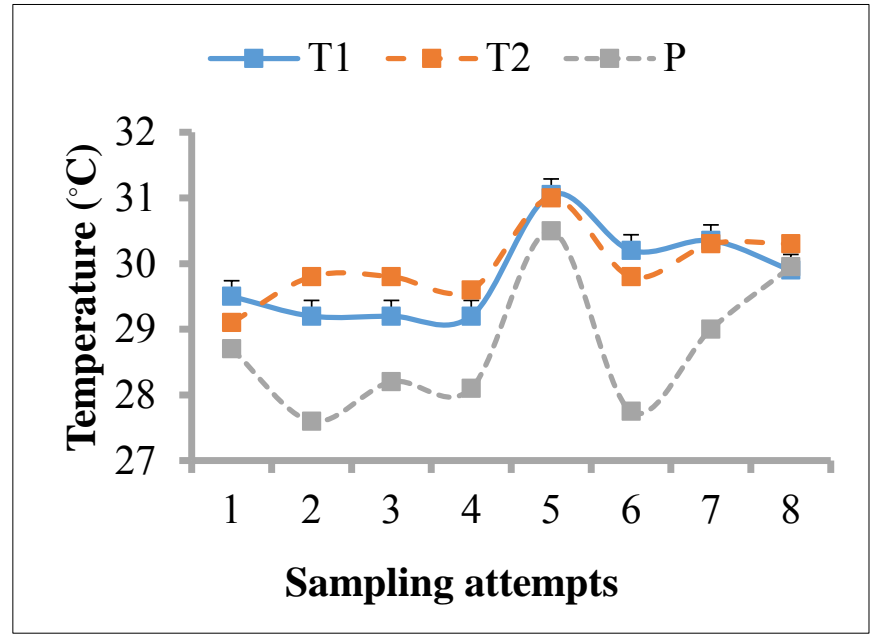

(a) Mean temperature variations

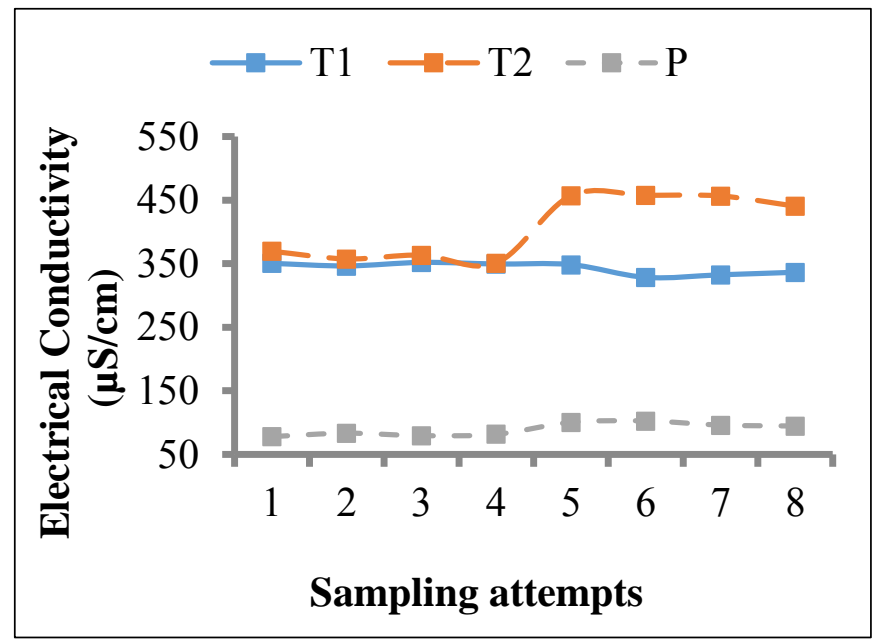

(c) Mean EC variations
(Mary et al., 2018; Shrimali et al., 2001). The statistical study of nitrite concentration of $\mathrm{T} 1, \mathrm{~T} 2$ and $\mathrm{P}$ shows statistical insignificance, since the $p$ value is $0.228(\alpha>0.05)$, therefore the null hypothesis cannot be rejected. That is, tube well water and pipe borne water not contaminated by nitrites and is within

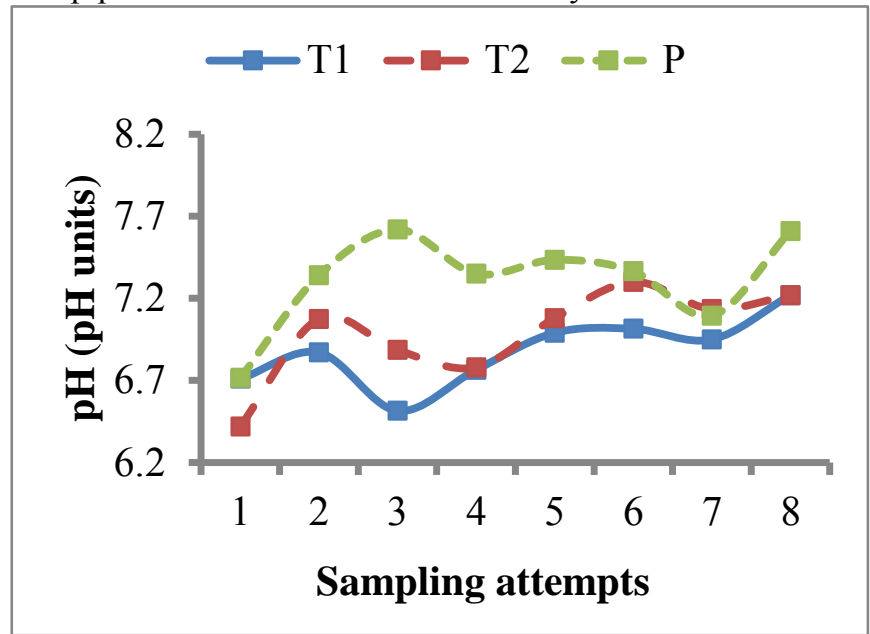

(b) Mean $\mathrm{pH}$ variations

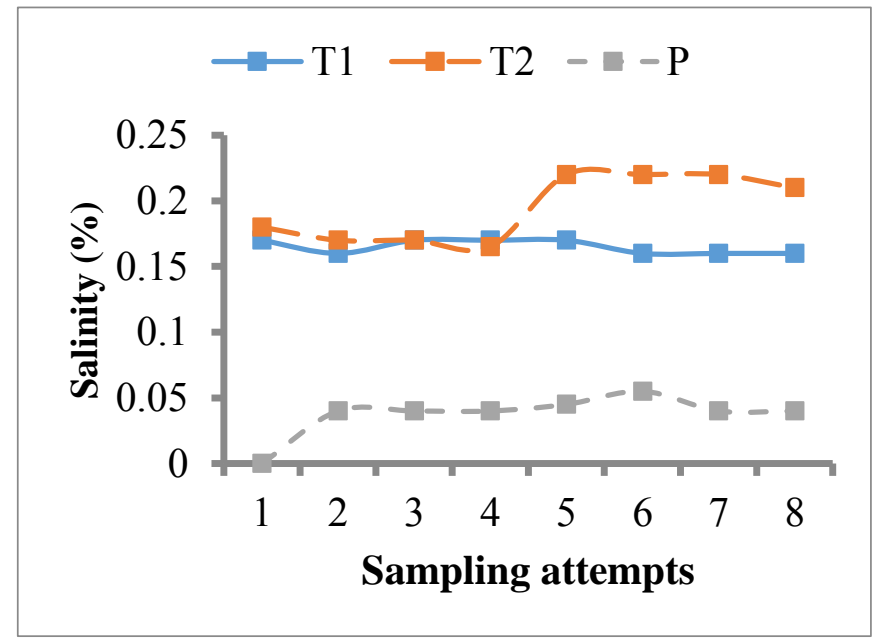

(d) Mean salinity variations

Figure 1. Mean Variations of Temperature, pH, EC, and Salinity (March 2020 - July 2020)

The mean nitrate concentration of the $\mathrm{P}(6.12 \pm 3.48) \mathrm{ppm}$ is higher compared to other two; which are T1 (4.343 \pm 1.130$)$ ppm and T2 (4.494 \pm 1.130$)$ ppm, yet they are very much smaller and within the permissible limit of WHO and SLS. The statistical study of nitrate concentration of T1, T2 and P, shows statistical insignificance since the $\mathrm{p}$ value is $0.228(\alpha>$ $0.05)$. Therefore, the null hypothesis cannot be rejected. It proves that the mean values of nitrates are almost equal. Therefore, the tube well water was not affected by any fertilizers or any other nitrate releasing sources. This proves that the tube well water and pipe borne water not at all contaminated by nitrates and are within the safe limit.

Major health implications of excess nitrate in water are hypertension in adults and methemoglobinemia in infants the safe limit. The mean nitrite concentration of the T1 $(0.1010 \pm 0.1183) \mathrm{ppm}$ is higher compared to other two; which are T2 $(0.05325 \pm 0.02823) \mathrm{ppm}$ and $\mathrm{P}(0.04137 \pm 0.02335)$ ppm, yet they are within the permissible limit of WHO and SLS. Phosphates enter into the ground water system from excessive use of chemical fertilizer in agriculture, sewage discharge and landfills by domestic waste. The mean phosphate concentration of the T1 $(0.1010 \pm 0.1183) \mathrm{ppm}$ is higher compared to other two; which are T2 $(0.05325 \pm 0.02823) \mathrm{ppm}$ and $\mathrm{P}(0.04137 \pm 0.02335) \mathrm{ppm}$, yet all are within the permissible limit of WHO and SLS. (Figure 2) 


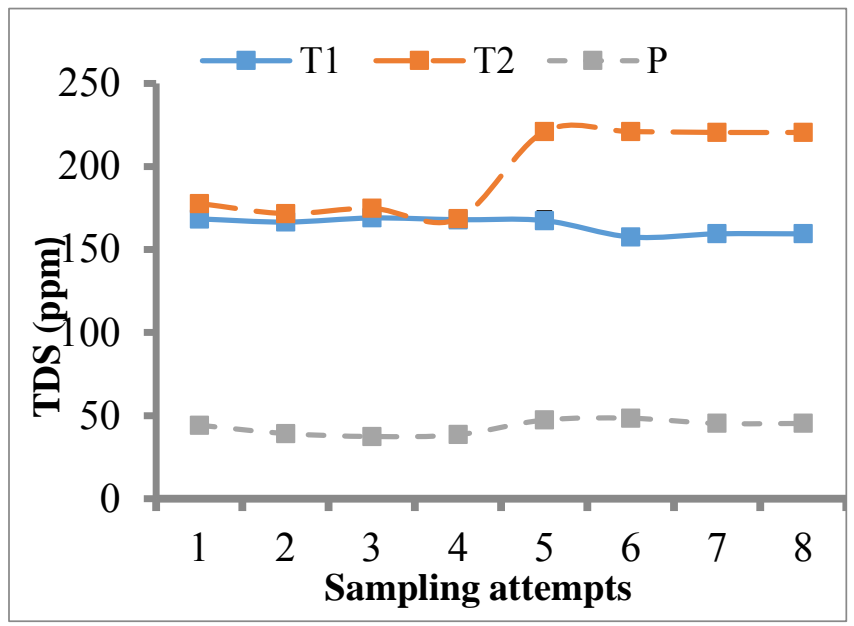

(e) Mean TDS variations

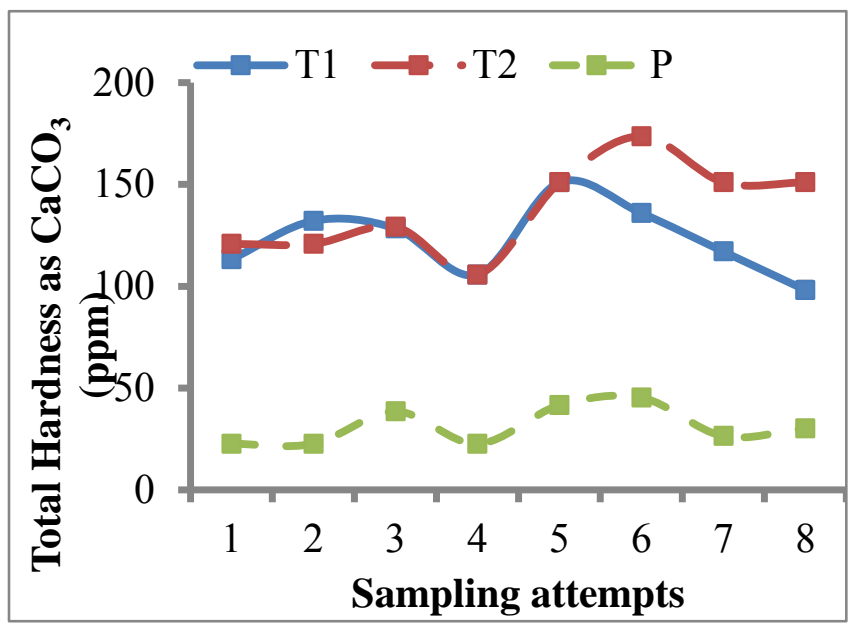

(g) Mean TH variations

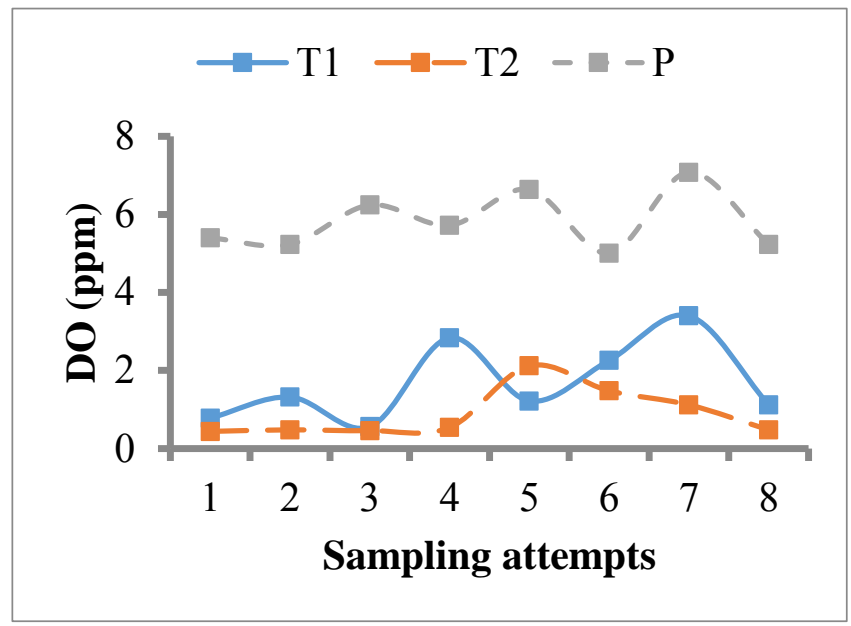

(f) Mean DO variations

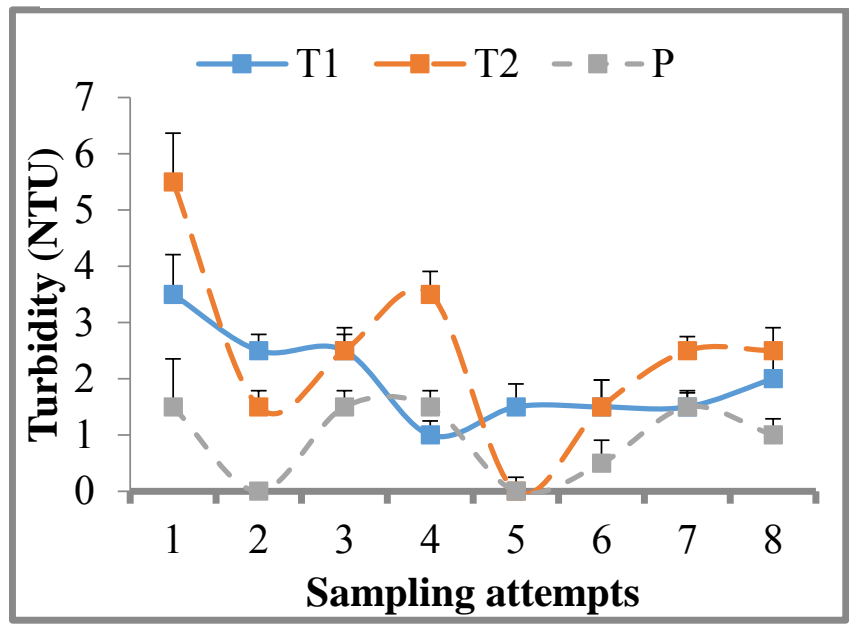

(h) Mean Turbidity variations

Figure 2. Mean Variations of TDS, DO, Total Hardness, and Turbidity (March 2020 - July 2020)

The statistical study of Phosphate concentration of T1, T2 and $\mathrm{P}$; shows statistical insignificance since the $\mathrm{p}$ value is 0.234 ( $\alpha$ $>0.05)$, therefore the null hypothesis cannot be rejected. This proves that the tube well water and pipe borne water are not contaminated by phosphates due to agricultural run offs and are within the safe limit (Asha et al., 2011). Since there are no landfills or sewage discharge within hostels the tube well water bodies were not contaminated by phosphates. Chloride present in water increases the electrical conductivity, thereby increasing its corrosive property of water. In metal pipes, chloride reacts with metal ions to form soluble salts, resulting in increased levels of metal concentration in drinking-water (Yanyu et al., 2019).

The mean chloride concentration of the T2 $(26.00 \pm 5.01) \mathrm{ppm}$ is higher compared to other two; which are T1 (24.25 \pm 4.06$)$ ppm and $\mathrm{P}(17.50 \pm 3.96) \mathrm{ppm}$, yet all three are within the permissible limit.

Presence of higher chlorides ions in tube wells are may be due to the sea water intrusion but still the chloride concentrations are within the desirable limit. Excessive intake of drinkingwater containing sodium chloride at concentration above $250 \mathrm{mg} / \mathrm{L}$ has been reported to produce hypertension; this effect is believed to be related to the sodium ion concentration (Kawasaki et al., 1978).

According to WHO the permissible of Fluoride concentration present in drinking water is $1.5 \mathrm{ppm}$ while permissible limit of Fluoride concentration according to SLS is $1 \mathrm{ppm}$. The mean Fluoride concentration of the T2 $(0.4188 \pm 0.2121) \mathrm{ppm}$ is slightly higher compared to other two; which are T1 $(0.2588 \pm 0.0808) \mathrm{ppm}$ and $\mathrm{P}(0.1850 \pm 0.1612) \mathrm{ppm}$, yet all three values are within the desirable limit. Fluorides are usually found in hard rock and leach into the groundwater if 
the groundwater becomes alkaline in nature (Gao et al., 2013). Since the tube well water is not alkaline there is no fluoride contaminations occurred. The mean iron Concentration of T2 $(0.896 \pm 0.687) \mathrm{ppm}$ is comparatively higher than $\mathrm{T} 1(0.854 \pm$ $0.433) \mathrm{ppm}$ and $\mathrm{P}(0.180 \pm 0.329) \mathrm{ppm}$ and both tube wells deviate from WHO and SLS.

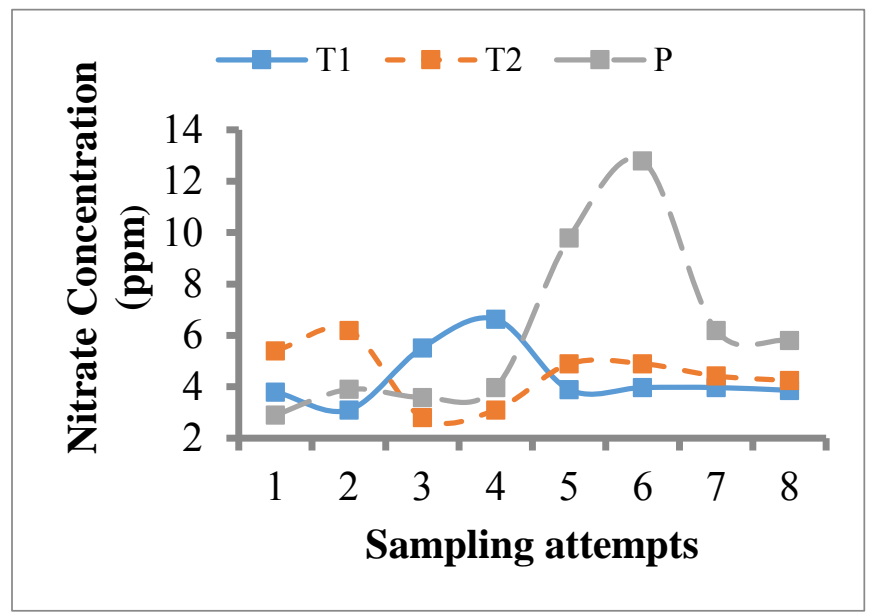

(i) Mean Nitrate variations

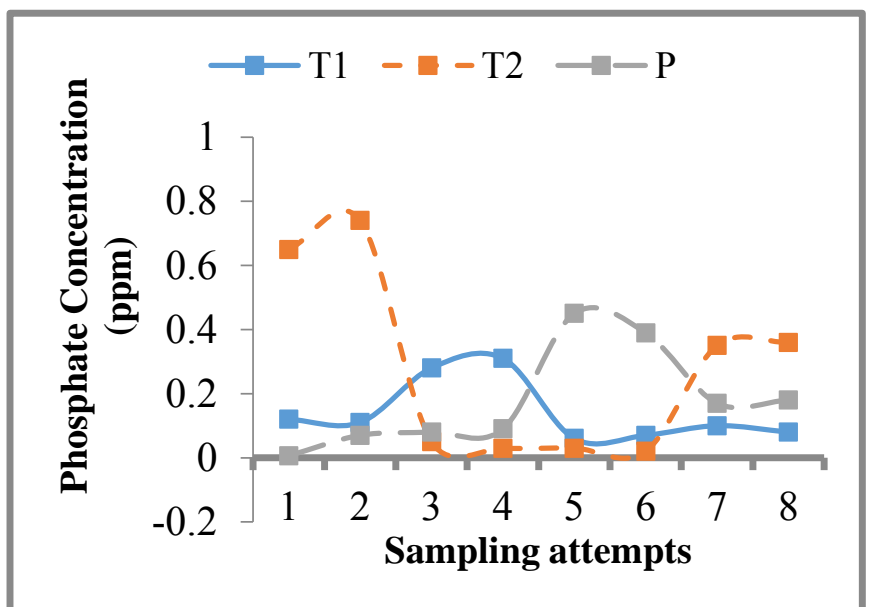

(k) Mean phosphate variations both tube wells by students have been stopped during this period. The statistical study of T1,T2 and P shows statistical significance since the $\mathrm{p}$ value is $0.036(\alpha<0.05)$, therefore, the alternative hypothesis can be accepted that is at least one mean

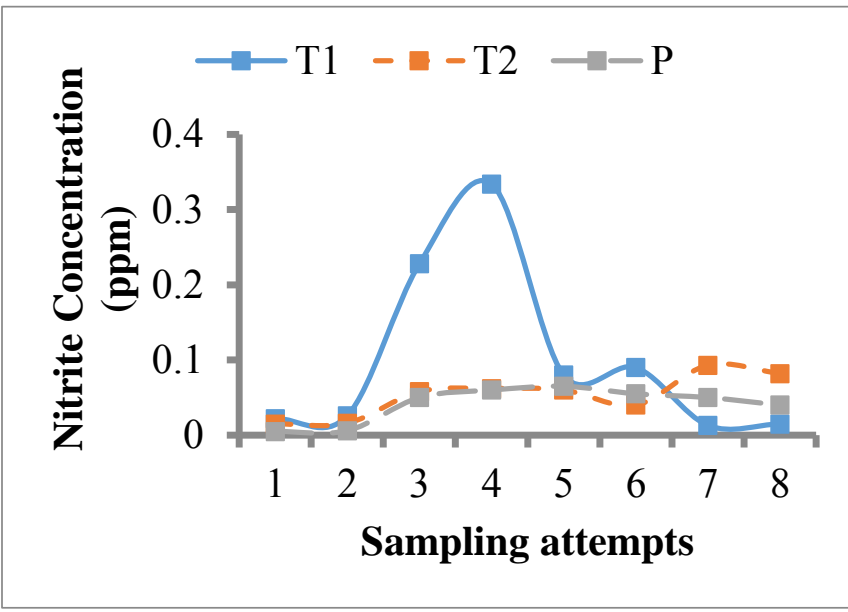

(j) Mean Nitrite variations

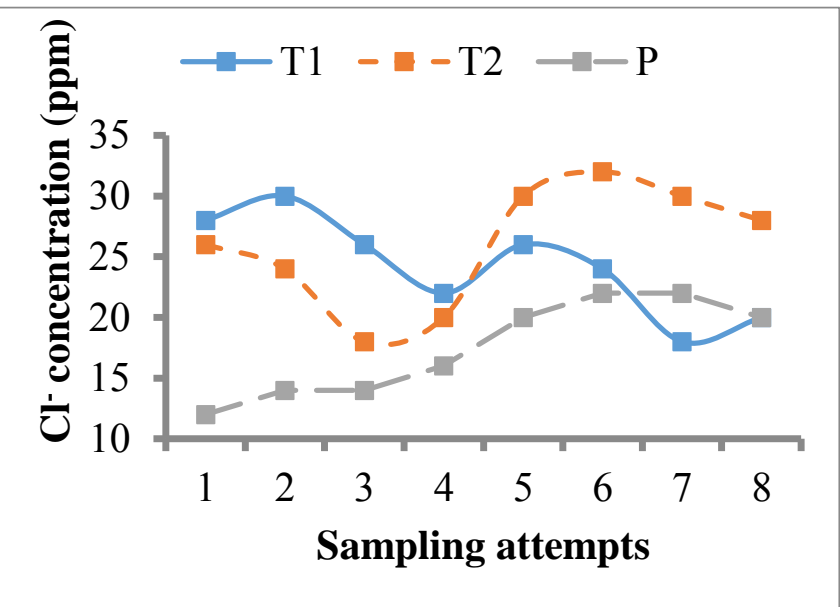

Figure 3. Mean Variations of Nitrate, Nitrite, Phosphate, and Chloride (March 2020 - July 2020)

value is different. Both the tube wells have higher iron concentrations and this may be released into water from the

corrosion of iron containing metals since the water is slightly acidic or from the groundwater contamination by nearby burial grounds which is located within $1 \mathrm{~km}$ radius range. The high concentration of iron has caused the tube well water slightly yellowish in colour and foul smelling (Hossain et al., 2013) Excessive iron has also caused yellow stains on clothes of students.(Figure 3)

High iron concentration is observed in both tube wells during $6,7,8$ sampling attempt and this may be due to release of iron into tube well water from natural deposit since the usage of
Calcium and magnesium are the major elements for the hardness of the drinking water. Hard water causes precipitate inside the pipes and boilers causing lower water flows and making for less efficient heating. The mean magnesium concentration of $\mathrm{T} 2(4.110 \pm 1.300) \mathrm{ppm}$ is comparatively higher than $\mathrm{T} 1(3.892 \pm 0.747) \mathrm{ppm}$ and $\mathrm{P}(1.451 \pm 0.477)$ ppm. Although the magnesium concentration T2 is higher than $\mathrm{T} 1$ and $\mathrm{P}$, all three (T1, T2 and P) are within the safe limit set by WHO and SLS. Therefore, the tube well and pipe borne water are not contamination by Magnesium. 


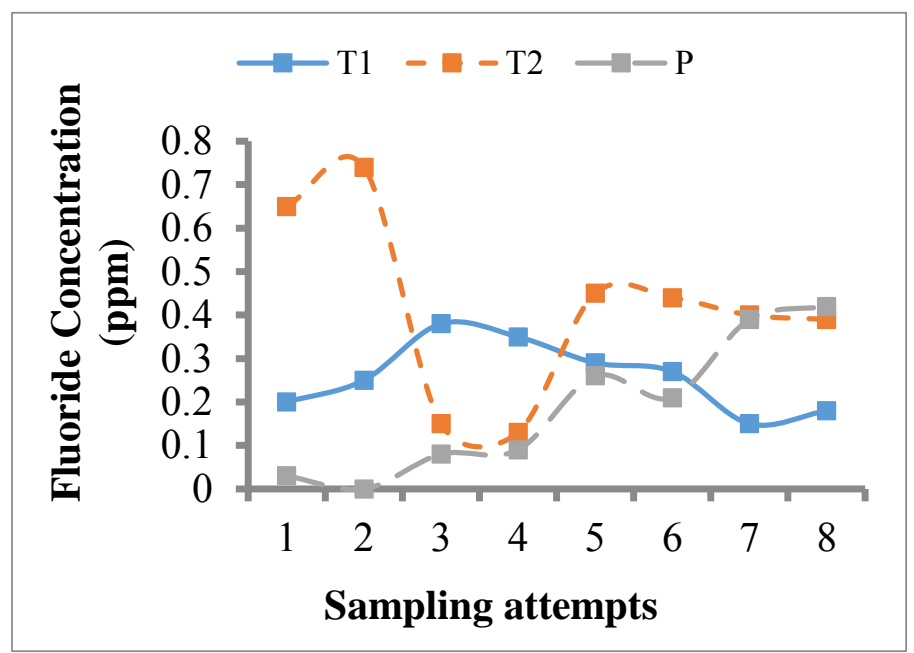

(m) Mean Fluoride variations

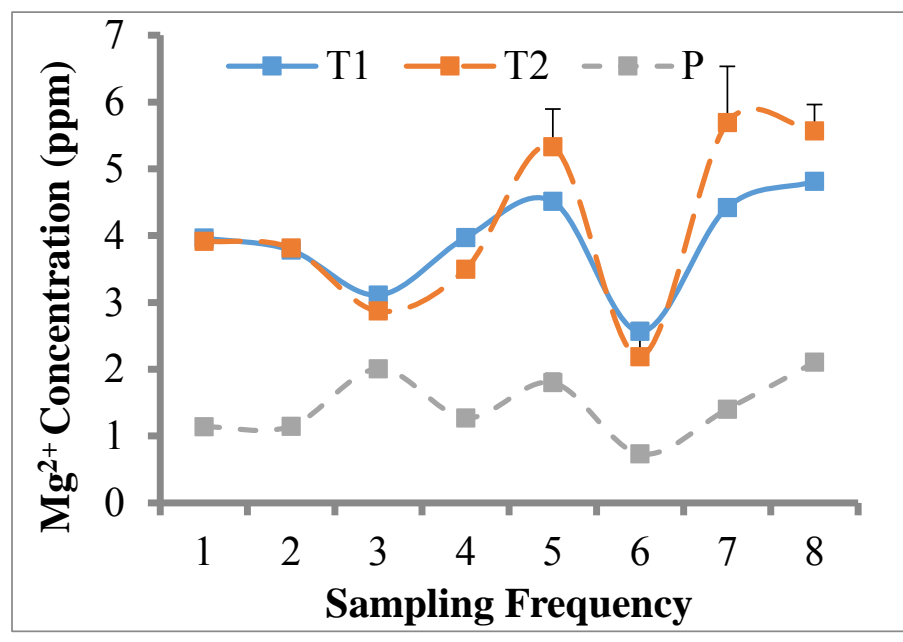

(o) Mean Magnesium variations

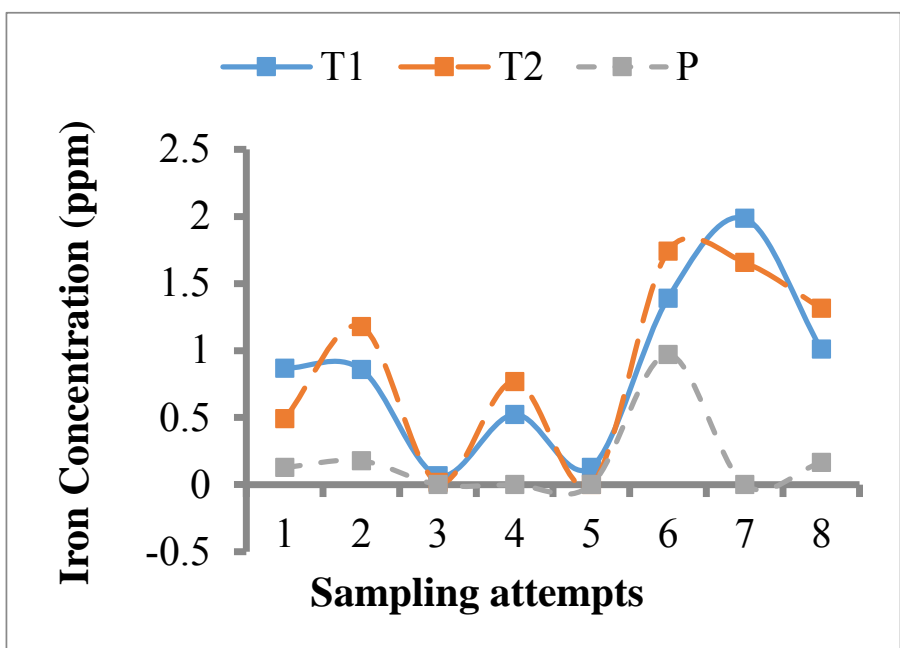

(n) Mean Iron variations

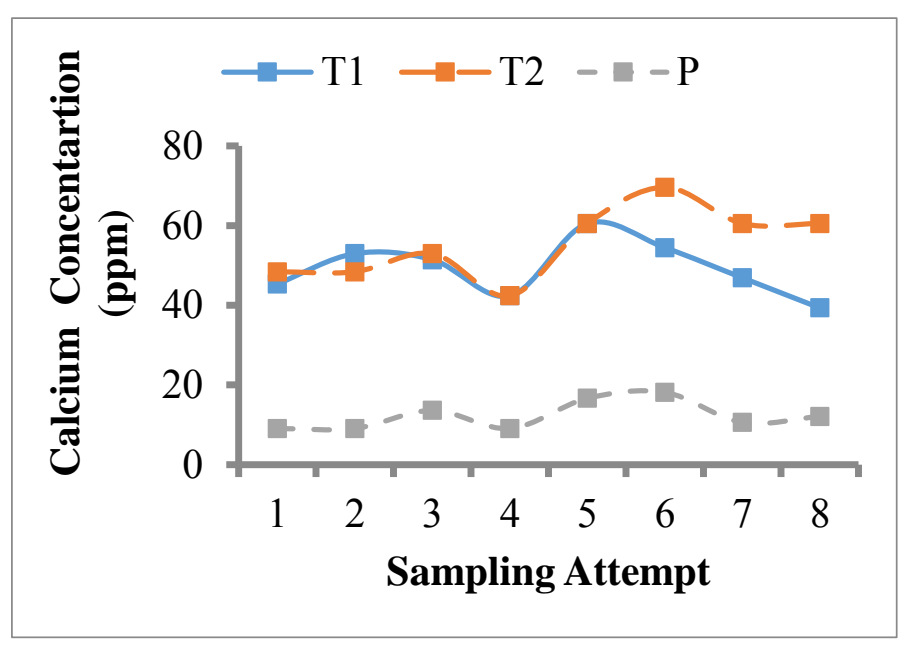

(p) Mean Calcium variations

Figure 4. Mean Variations of Fluoride, Iron, Magnesium, and Calcium (March 2020 - July 2020)

The mean Calcium concentration of the T2 (55.41 18.89$) \mathrm{ppm}$ is the highest compared to other two; which are T1 (49.17 \pm 6.96$)$ ppm and $\mathrm{P}(12.29 \pm 3.57) \mathrm{ppm}$. All T1, T2, P are within the WHO safe limit. High amount of calcium concentrations was observed during 6, 7, and 8 sampling attempts for T2. The ions in hard water can also corrode metal pipes through galvanic corrosion (Arabi et al., 2013). When one takes up large amounts of calcium this may negatively influence human health. The lethal dose of oral uptake is about $5-50 \mathrm{mg} / \mathrm{kg}$ body weight.

According to Environmental Quality Standard (EQS) the safe limit of Potassium concentration of the drinking water is 12 ppm. The mean Potassium concentration of the T1 (23.689 \pm 1.448$) \mathrm{ppm}$ is higher compared to other two; which are T2 (19.726 \pm 1.411$) \mathrm{ppm}$ and $\mathrm{P}(4.753 \pm 1.211) \mathrm{ppm}$. T1 and $\mathrm{T} 2$ in all sampling attempts (1-8) showed deviation from the safety limit of EQS standards while the pipe born water is within the safety limit.
The statistical analysis shows that there is a statistical significance since the $\mathrm{p}$ value is $0.000(\alpha<0.05)$ so the alternative hypothesis can be accepted that is at least one mean value is different. However, increased exposure to Potassium could result in significant health effects in people with kidney disease or other conditions, such as heart disease, coronary artery disease, hypertension, diabetes (Pohl et al., 2013). (Figure 4)

The mean chromium value of the T1 $(0.306 \pm 0.442) \mathrm{ppm}$ is the lowest compared to other two; which are T2 $(0.293 \pm 0.411)$ ppm and $\mathrm{P}(0.199 \pm 0.359) \mathrm{ppm}$. All T1, T2, P at all sampling attempts was above the permissible limit of WHO and SLS. This can be due to the lack of sensitivity of AAS which results in the higher chromium value. Statistical study of Chromium concentration of Tube well 1, Tube well 2 and Pipe borne water shows statistically insignificant since the $\mathrm{p}$ value is $0.848(\alpha>0.05)$, since all values are equal. Therefore, it proves that all mean values are equal. The main health problems seen 
in animals following ingestion of chromium (VI) compounds are to the stomach and small intestine (irritation and ulcer) (Donald G. Barceloux et al., 1999).

The mean cadmium value of the T1 $(0.0145 \pm 0.0294) \mathrm{ppm}$ is the highest compared to other two; which are T2 $(0.01238 \pm 0.02331) \mathrm{ppm}$ and $\mathrm{P}(0.00912 \pm 0.02120) \mathrm{ppm}$. All T1, T2, P are within the WHO safe limit. Cadmium is heavy metals usually leach into the ground water table from industries, excessive use of nitrogen fertilizers, pollution through irrigations and atmospheric irrigations, since the hostels are located in a remote area. Cadmium concentration is found to be so low (Chien-Min et al., 2006). Levels of cadmium could be higher in areas supplied with soft water of low $\mathrm{pH}$, as this would tend to be more corrosive in plumbing systems containing cadmium. (Figure 5)

\section{CONCLUSION}

Pipe borne water is within the permissible limit set by both WHO and SLS for all physiochemical parameters, while T1 and T2 agrees with the WHO and SLS only for Temperature, $\mathrm{pH}$, TDS, Total Hardness, Nitrate, Nitrite, Phosphate, Chloride, Fluoride, Magnesium, Calcium and Cadmium parameters. T1 and T2 deviates from the WHO and SLS for Salinity $\quad(0.165 \pm 0.01, \quad 0.194 \pm 0.03), \quad$ DO $\quad(1.688 \pm 1.025$, $0.890 \pm 0.628)$, Turbidity $(2.000 \pm 0.802,2.438 \pm 1.613)$, Iron $(0.854 \pm 0.637, \quad 0.896 \pm 0.687), \quad$ Potassium (23.689 \pm 1.448 , $19.726 \pm 1.41)$, and Chromium parameters $(0.306 \pm 0.442$, $0.293 \pm 0.411)$ while only $\mathrm{T} 2$ deviates from the standards for EC (406.6 \pm 50.0$)$ while T1 is within the standards set by WHO. Therefore, it is concluded that the both tube wells are not suitable for consumption and for washing since they are high in Iron, Chromium, Potassium, Turbidity and Salinity but can be used for irrigation purposes while pipe borne water is advisable for consumptions.

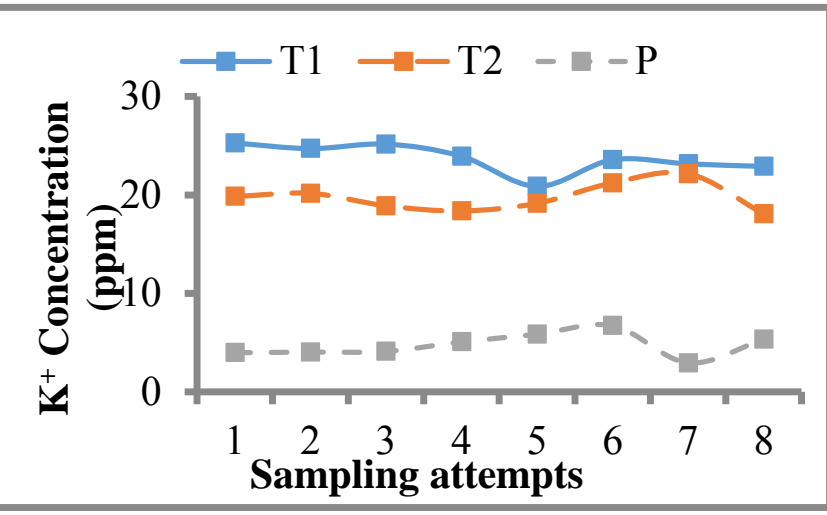

(q) Mean Potassium variations

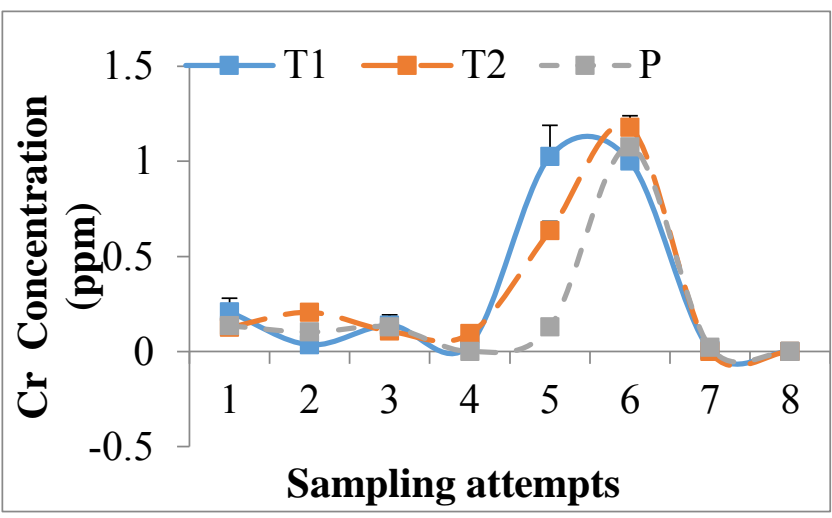

(r) Mean Chromium variations

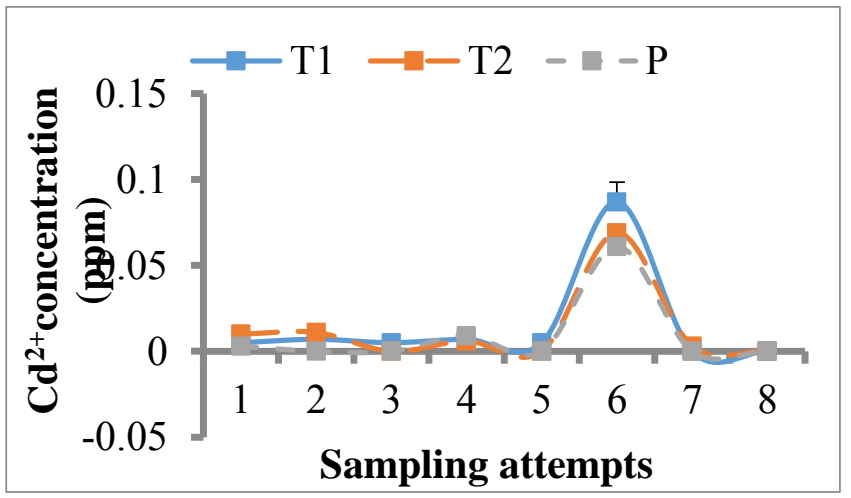

(s) Mean Cadmium variations

\section{Acknowledgement}

Authors are acknowledged to Mr. A.J.M. Harris for his assistance during this study. 


\section{REFERENCES}

Abdelkader, T. A. and Brahim, A., 2016. Seawater intrusion impacts on the water quality of the groundwater on the North West coast of Oman, Water Environment Research, 88(8), pp. 732-739.

Arabi, A.S., Funtua, I.I., Dewu, B.B.M., Garba, M.L., Okoh, S., Kwaya, M.Y. and Bolori M.T., 2013. Assessment of Calcium and Magnesium concentrations in groundwater as supplements for sleep related ailments, J.Appl.Environ.Biol.Sci, 3(7), pp. 29-35.

Asha, L.S., Tripathi, A.K., Aniruddha, K. and Singh, V.K., 2011. Nitrate and phosphate contamination in ground water of Varanasi, Uttar Pradesh, India, Journal of Industrial Research and Technology, 2(1), pp. 26-31.

Chien-Min, C. and Ming-Chao L., 2006. Ecological risk assessment on a Cadmium contaminated soil landfill- a preliminary evaluation based on toxicity tests on local species and site-specific information, Science of the total environment, 359(1-3), pp. 120-129.

Donald G. Barceloux and Dr. Donald Barceloux., 1999. Chromium, Journal of Toxicology, Clinical Toxicology, 37(2), pp. 173-194.

Durowaye, S.I., Alabi, A.G.F., Sekunowo, O.I., Bolasodun, B. and Rufai I.O., 2014. Effects of $\mathrm{pH}$ variation on corrosion of mild steel in bore-hole water using $1 \mathrm{M}$ Sodium hydroxide solution. International Journal of Engineering and Technology, 4(3), pp. 139-143.

Foster, S.S.D. and Chilton, P.J., 2003. Groundwater: the processes and global significance of aquifer degradation. Phil.Trans.R. Soc.Lond, 358, pp.1957-1972.

Gao, S., Cui, J. and Wei, Z., 2013. Study on the fluoride adsorption of various apatite materials in aqueous solution, $\mathrm{J}$ Fluor Chem, 130, pp. 1035-1041.

Hossain, D., Islam, M.S., Sultana, N. and Tusher R., 2013. Assessment of Iron contamination in groundwater at Tangail municipality, Bangaladesh, J.Environ.Sci. \& Natural Resources, 6(1), pp. 117-121.

Kawasaki, T., Delea, C.S. and Bartter, F.C., 1978. The effect of high-sodium and low-sodium intakes on blood pressure and other related variables in human subjects with idiopathic hypertension, Am J Med, 64, pp. 193-8.

Mary, H.W., Rena, R.J., Jean, D. B., Theo, M.K., Peter, J.W., Bernard, T.N., Cristina, M. V. and Simone, G.B., 2018. Drinking water Nitrate human health: An updated review, Int J Environ Res Public Health, 15(7), pp. 1557.
Masaki, H. 2004. Temperature- Electrical conductivity relation of water for environmental monitoring and geophysical data inversion, Environmental monitoring and geophysical data inversion, 96(1-3), pp. 119-28.

Patil, V.T. and Patil, P.R., 2011. Groundwater quality of open wells and tube wells around Amalner Town of Jalgaon District, Maharashtra, India, E-Journal of Chemistry, 8(1), pp. 53-58.

Paul, B., Florent, B., Jose, L., García, A., Christian, L., Yves, T. and David, M.V., 2013. Impacts of human activities on recharge in a multi-layered semiarid aquifer, hydrological process, 28(4), pp. 2223-2236.

Peel, Murray C., McMahon, Thomas A. and Finlayson, Brian L., 2004. Continental differences in the variability of annual runoff: update and reassessment. Journal of Hydrology, 295(1-4), pp. 185-197.

Pohl HR., Wheeler JS., Murray HE., 2013. Sodium and potassium in health and disease. Met Ions Life Sci., 13, pp. 2947.

Robert, J. and Davies, C., 2007. Turbidity, Suspended Sediment, and Water Clarity: A review, JAWRA, 37(5), pp. 1085-1101.

Shrimali, M. and Singh, K.P., 2001. New methods of nitrate removal from water. Environmental Pollution, 112(3), pp. 351-9.

Simon, G., Danby, Kristy, B., Andrew, M.W., John, C., Phyoe, K.P., Carsten, F. and Michael J.C., 2018. The effect of water hardness on surfactant deposition after washing and subsequent skin irritation in atopic dermatitis patients and healthy control subjects, Journal of Investigative Dermatology, 138(1), pp. 68-77.

Siriwardana, C., Asitha T. Cooray., Sudantha S. Liyanage. and Koliyabandara, S. M. P. A., 2019. Seasonal and Spatial Variation of Dissolved Oxygen and Nutrients in Padaviya Reservoir, Sri Lanka, Journal of Chemistry, 2019, pp. 1-11.

Tiwari, A.K., Singh, A.K., Singh, A.K. and M. P. Singh., 2017. Hydrogeochemical analysis and evaluation of surface water quality of Pratapgarh district, Uttar Pradesh, India. Appl Water Sci. 7, pp.1609-1623.

Yanyu, C., Yongxiang, Q., Dilinuer, D. and Yujun, W., 2019. The effect of Chlorine ion on metal corrosion behavior under the scratch defect of coating, International Journal of Corrosion. Hindawi, 2019, pp. 1-11.

Zakowski, K., Narozny, M., Szocinski, M. and Darowicki K., 2014. Influence of water salinity on corrosion risk-the case of the southern Baltic Sea coast, Environmental Monitoring and Assessment 186(8), pp.4871-4879. 